\title{
A memória coletiva de mulheres nordestinas como subsídio identitário no processo criativo do espetáculo Bonita Maria
}

\author{
La memoria colectiva de las mujeres del noreste como un subsidio a la \\ identidad en el proceso creativo del espectáculo Bonita Maria
}

The collective memory of northeastern women as an identity subsidy in the creative process of the spectacle Bonita Maria

\section{Hélder Paulo Cordeiro da Nóbrega ${ }^{1}$}

\begin{abstract}
Resumo
O artigo aborda o processo criativo do espetáculo Bonita Maria, tendo como substrato indenitário a memória coletiva de mulheres nordestinas, e dos seus integrantes, imbricando o estudo de caso com uma pesquisa participante, subsidiados pelas teorias da transcriação e da crítica do processo.
\end{abstract}

Palavras chave: Artes cênicas; artes visuais; crítica do processo; mulher no cangaço; transcriação.

\section{Resumen}

El artículo aborda el proceso creativo del espectáculo Bonita Maria, teniendo como sustrato de indemnización la memoria colectiva de las mujeres del noreste, y sus miembros, imitando el estudio de caso con una investigación participante, subvencionada por las teorías de la transcrición y la crítica del proceso.

Palabras clave: Artes escénicas; artes visuales; crítica del proceso; mujer en el cangaço; transcreación.

\begin{abstract}
This article describes the creative, textual and visual process, of the spectacle Bonita Maria, having as an indemnity subtract the collective memory of northeastern women and they participants, interweaving the case study with participatory research, allied to the theory of transcreation and the process's critics.
\end{abstract}

Keywords: Scenic arts; visual arts; process's critics; woman in cangaço; transcreation.

\section{Introdução}

Bonita Maria é um espetáculo apresentado como culminância da disciplina Técnicas do Teatro e da Dança, do curso de Artes Cênicas na UFPB, no ano de 2011. Com direção de Elias de Lima, professor da referida matéria, interpretado pela atriz Aline Lima, aluna

\footnotetext{
1 Mestrando em Artes Visuais; Programa Associado de Pós-Graduação em Artes Visuais - PPGAV UFPB/UFPE; João Pessoa, Paraíba, Brasil; heldercinema@gmail.com.
} 
concluinte, o projeto contou com a elaboração do texto e concepção visual de Hélder Nóbrega, discente dos cursos de extensão das referidas, formação e instituição.

Esse escrito contém o liame entre as artes visuais e a literatura, na especificidade da dramaturgia, abordando o processo criativo da peça, com enfoque em seus construtos textuais e visuais. Todavia, o subsídio encontrado para essas elaborações, são os aspectos indenitários encontrados na memória coletiva de mulheres nordestinas, bem como a vivência da própria atriz susodita, com outras experiências advindas do teatro de rua.

O dramaturgo, também é o responsável pela criação plasticidade do referido espetáculo, junto com seus demais integrantes, compõe o grupo de pesquisa teatral intitulado Semente Contemporânea. Dessa forma, esse artigo caracteriza-se por uma pesquisa participante, pois, contém, intrínseco em seu escopo, relatos dessas personas em suas funções revisitadas.

Imbrincado também à um estudo de caso, por conter coleta e análise de dados, o escrito é respaldado pela teoria da transcriação (CAMPOS, 2011) e na crítica do processo (SALLES, 2017), com os quais esboça o referido processo de criação em seu fenômeno, textual, visual e auditivo, levando em consideração o caráter coletivo de seu construto, entrelaçado à participação ativa da atriz, já menciona, bem como o diversificado universo feminino que permeia toda a obra, assim como o seu processo criativo.

Maria Bonita ou Maria do Capitão, esposa de Lampião, é um dos ícones de maior representatividade na cultura do nordeste do Brasil, no que diz respeito à construção visual da mulher nordestina, encontrada na cultura popular em grandes feiras e mercados públicos, manifestada em diversificados suportes e materiais, por toda a região. Entretanto, Maria Déa, como era conhecida antes de se juntar ao afamado grupo do cangaço, teve sua importância histórica, assim como as demais mulheres, posta à sombra da figura de seus maridos, no caso de Maria do Capitão, o então rei do cangaço, Virgulino Ferreira. Tal fato evidencia-se nas diversas mídias que relatam a história do casal: livros, filmes, pinturas, programas de televisão, música, literatura de cordel, dentre outros meios de linguagem.

A princípio se faz necessário esclarecer que existe uma considerável literatura acerca do que teria sido efetivamente o cangaço, alguns autores vêem o movimento pelo âmbito criminal, outros em seu aspecto cultural. Para não ficar nas dicotomias conceituais, optamos pelo o que relata o historiador Mello (2000), que estuda o cangaço em seu fenômeno estético. Para esse historiador, a violência rural e o banditismo nos moldes em que permeiam a sociedade sertaneja, o cangaço se apresenta "como fenômeno que durante tantas décadas e ao longo de séculos caracterizou a existência rural do nordeste do Brasil e no estudo da 
funcionalidade como fenômeno muitas vezes eu me deparava com aspectos mais de arte que de ciência." (MELLO, 2000, online).

Um dos objetivos neste espetáculo, era justamente o seu fenômeno estético, criar tantos os aspectos visuais, quanto a sua dramaturgia com o intuito contribuir para que a figura feminil, ao ser construída para a cena, fosse concomitante ao arquétipo existente e resistente nas memórias coletivas e memórias individuais de mulheres nordestinas. Nesse seguimento, buscou-se suporte na tese de Halbwachs (1990) uma vez que, para esse autor, a memória histórica é guardada em livros e documentos acerca de determinados fatos, numa lógica cronológica de ocorrências. Já a memória coletiva, "seria a história deste caráter impessoal, desta precisão abstrata e desta relativa simplicidade que dela fazem precisamente um quadro sobre o qual nossa memória individual poderia se apoiar”. (HALBWACHS, 1990, p.60).

Para o espetáculo Bonita Maria, foi realizado uma pesquisa acerca da forma com as quais as mulheres enxergavam o cânone da Maria Bonita. Com base nesse levantamento da lembrança popular, foi elaborado o texto, em sincronia com as observações dos dados referentes às possibilidades de construções visuais. Dessa forma, buscara-se encontrar as visões acerca da vida dessa mulher cangaceira, presente na memoração conjunta feminina. Os motivos que a insuflaram em busca das alternativas de melhor viver, distante das realidades adoecidas nas quais, um corpo feminino está inserido, concomitante à tentativa de romper com os paradigmas patriarcais sufocantes e opressores, existentes com mais ênfase no século passado.

Nessa compreensão, as lembranças de algumas mulheres elencadas para esse estudo, tendo em mente os grupos sociais das quais faze parte, trazem dados importantes sobre esse modelo feminil do cangaço, em suas memórias individuais e coletivas levando em consideração o que diz Halbwachs (1990) acerca da inexistência de uma lembrança pura, uma vez que essa é uma reconstrução do passado. "A lembrança é em larga medida uma reconstrução do passado com a ajuda de dados emprestados do presente e, além disso, preparada por outras reconstruções feitas em épocas anteriores. " (HALBWACHS, 1990, p. $71)$.

Sendo assim, diante da multiplicidade dessas memórias feminais, criar por meio de imagens e textos torna-se um processo de criação interessante para se discutir, tendo em mente os aspectos socioculturais nos quais estão inseridos tanto esses repositórios humanos de lembranças coletivas, quanto os artistas envolvidos na composição da obra. Desse modo, este escrito apresenta uma prática artística, na especificidade da dramaturgia e composição visual, imbrincada há outros setores criativos que compõem o fazer teatro, arte prioritariamente feita 
em coletividade. Tais demandas elencadas em seções objetivam a compreensão deste processo de criação.

\section{Semente Contemporânea: uma breve contextualização}

Bonita Maria, é um espetáculo de teatro, realizado pelo grupo de estudos e pesquisa em poéticas da cena, intitulado Semente Contemporânea. Composto por três integrantes fixos e mais dois colaboradores externos, na especificidade da obra teatral susodita. O grupo foi criado em 2011, durante a gestão do projeto investigado, e propiciou o surgimento de outras atividades relacionadas as artes cênicas, em outras experiências com espetáculos e performances, não contempladas nesse estudo, pois o mesmo se atém às necessidades do seu recorte.

Sementes plantadas nas trevas das incertezas do presente, mas que almejam ser iluminadas pelas luzes de um futuro ainda por vir, cujo o mesmo só será revelado com o desfecho dos acontecimentos pósteros. (AGAMBEN, 2009). Nessa perspectiva, o grupo compreende sua atuação tal qual uma semente, com toda sua capacidade de gerir um mundo, ou seja, um universo de desdobramentos que o teatro possibilita. Tais semeaduras, no tempo cronológico, nas quais surgem, podem reverberar em diversas situações vindouras, a exemplo de escritos acadêmicos ou outras pesquisas em artes.

Na primeira reunião da equipe, foram estabelecidas metas e responsabilidades para cada um dos integrantes. A tríade ficara composta pelo diretor, a atriz e o dramaturgo, no entanto havia o entendimento que eram necessários outros elementos tão importantes quanto o tríduo mencionado. "Processos coletivos, como no caso do cinema, do teatro, da dança e da música. São manifestações artísticas que envolvem um grupo de artistas e técnicos, que desempenham papéis de uma grande diversidade”. (SALLES, 2007, p.49-50).

Dessa forma, entra em cena a dupla tarefa do dramaturgo artista visual, responsável pela cenografia e a composição visual da mise en scène, concomitantes entre si. Vale destacar que houve a presença do figurinista, aderecista e sonoplasta Adriano Bezerra, bem como a iluminadora Mayara Costa. A equipe composta, sempre orientada pelo diretor do espetáculo, Elias de Lima, responsável por todas essas decisões envolvendo o processo criativo do espetáculo como um todo.

\section{Bonita Maria: o processo de criação}


Antes de tudo se faz necessário pontuar algumas observações, compreendemos o processo de criação como uma transcriação, teorizada por Campos (2011). Em acordo com esse autor referenciado, tudo que está na ordem dos pensamentos ao se organizarem em formas de ideias, e manifestados numa linguagem, a exemplo da escrita é um ato de tradução e recriação, ou seja, uma transcriação, de modos que a mente une vários elementos em seus significados em prol da construção de algo novo.

O espetáculo, Bonita Maria, teve algumas características particulares em seu processo criativo, no qual havia a necessidade de criar um texto e uma visualidade, que propiciasse ser apresentada tanto em palcos, quanto em espaços alternativos por meio da performance. Tal fato abriu margem considerável às interações com um diversificado público, a depender do território no qual se apresentava. "O artista é aquele que fixa e torna acessível aos mais "humanos" dos homens o espetáculo de que fazem parte sem vê-lo". (MERLEAU-PONTY, 2004, p.134).

Para nós, o pensamento de Merleau-Ponty é importante devido sua aplicabilidade ao teatro, pois, esse filósofo, diferente da ciência positivista, une corpo e o espírito esclarecendo que sensações em suas subjetividades, se tornam perceptíveis através dos gestos, palavras e do corpo, assim como no teatro, "em ações que o espírito e o corpo se mesclam". (ALVES, 2010, p.228).

Seguindo o pensamento de Alves (2010), podemos ir mais longe, uma vez que a pesquisadora explica sobre nossas sensações subjetivas, a exemplo da ira, embasadas no raciocínio merleau-pontiano, diz a autora: "A raiva não é matéria, não posso tocá-la, mas posso perceber sua presença pela manifestação do outro". (ALVES, 2010, p. 227). Ademais, o que seria o teatro senão o encontro presencial com outro, por meio das emoções representadas, ou seja, a experiência de se observar vidente, num corpo que se faz visível a nós, de maneira muito mais potente, trabalhada pelo jogo do espetáculo, em suas formas sensíveis estéticas. Por esse ângulo, destacamos ainda a fala da estudiosa supracitada.

A principal ferramenta de trabalho do artista é como se reconhecer e fazer reconhecer no outro um novo sentido que só é possível pela sua expressão. $\mathrm{O}$ principal fundamento desse reconhecimento é a imbricação de experiências sensíveis estéticas - que estão envolvidas no contato com o outro, por exemplo, com aquele que nos fala. (ALVES, 2010, p.228).

$\mathrm{Na}$ área da arte, tais operações expressivas só ocorrem em detrimento de um ordenamento logístico. Organizar o pensamento se faz necessário, tendo em vista a 
pluralidade das ideias que surgem nas fases que compõe toda a elaboração dos processos de criação, bem como a diversidade de materiais resultantes deles. A ideia sobre uma luz pontual, afim de obter uma determinada atmosfera, pode surgir numa marcação da atriz, ou numa leitura, isso influi diretamente nas cores, formas e texturas dos elementos visuais colocados na cena. Nessa acepção Zamboni (2006) nos alerta que ato criativo é organizacional "a criação, na realidade, é um ordenamento, é selecionar, relacionar e integrar elementos que em princípio pareciam impossíveis". (ZAMBONI, 2006, p.34).

Para além das necessidades de uma pesquisa, sobre a vida da mulher no cangaço disponível na literatura vigente, foi verificado pelo processo demandas relacionadas a memória coletiva, imbrincada com as memórias individuais, uma vez que todos temos nossa memória individual (pessoal) apoiada pela memória coletiva (social), ou seja, carregamos impressões dos grupos sociais que convivemos. (HALBWACHS, 1990).

Dessa forma, buscar subterfúgios na memoração de mulheres nordestinas é pertinente quando verificado que o cangaço se estendeu ao longo de cinco séculos, por toda a região Nordeste, tendo seu fenômeno social e estético melhor elaborado a partir dos anos 1930, amadurecendo nos últimos dez anos de sua existência, com a presença feminil. (MELLO, 2000, online). O processo de criação observou que um olhar mais atento acerca das memorias coletivas femininas provindas de algumas localidades, produzidas em seus grupos de origem, enriqueceriam o texto e, por conseguinte à obra.

Outrossim, relativo a um processo criativo, que vê em sua estrutura fundante, a necessidade de ir em busca dessas memórias coletivas femininas, está no fato de que a literatura existente, sobre desta figura feminal no cangaço é, majoritariamente, escrita por homens. Desejamos com nosso processo quebrar essa estereotipação masculina com relação ao universo feminino. Corroborando com nossa escolha, trazemos o pensamento de Perrot (2007, p.22-23), em sua obra Minha história das mulheres, nela a autora nos diz que desde os livros bíblicos, a exemplo da primeira Epístola à Timóteo, escrita por Paulo, há orientações específicas para o silenciamento das mulheres. Essa gênese reverbera no mundo ocidental, em demais linguagens situadas numa diversidade de mídias, ao longo da história.

Em compensação existe uma abundância, e mesmo um excesso, de discursos sobre as mulheres; avalanche de imagens, literárias ou plásticas, na maioria das vezes obra dos homens, mas ignora-se quase sempre o que as mulheres pensavam a respeito, como elas as viam ou sentiam. (PERROT, 2007, p.22). 
Voltando ao pensamento de Mello (2000), por ter um estudo relevante acerca da estética do cangaço, no documentário de sua autoria nomeado A Estética do Cangaço, rendas, bordados e linhas coloridas, adereçavam os trajes de um dos guerreiros mais exóticos, em termos de visualidades, existentes no mundo. Tal ênfase ficara marcante nos vestuários desses combatentes depois da introdução das mulheres ao grupo. Maria do Capitão, a Maria Bonita como hoje a conhecemos, foi percursora desse movimento estético, dentro do cangaço, ela em diversas situações protagonizava essa necessidade visível da mulher concomitante à vaidade do restante do grupo.

Há relatos, destacados por historiadores que as rendas dos bornais, que tanto embelezaram os trajes do cangaço, foram concebidas por mulheres ingressante ao bando como Dadá e a própria Maria Bonita. Entretanto, destacamos que os homens cangaceiros também participavam ativamente, bordando e costurando, tendo como referencial os depoimentos de ex-integrantes desses grupos, sobretudo, as cangaceiras.

Encontrar essa mulher, presente no tempo contemporâneo, resistente e existente na memória das mulheres nordestinas, situadas no campo de atuação do referido grupo de pesquisa teatral, o estado da Paraíba e de outras comarcas vizinhas, foi um exercício laboratorial, que propiciou uma melhor explanação do universo nordestino feminal, tendo em mente que "toda memória coletiva tem por suporte um grupo limitado no espaço e no tempo". (HALWBACHS, 1990, p.86).

Tal decisão dramatúrgica, por envolver noções de tempo e espaço, territorialidade e cultura, foi compartilhada coletivamente com os demais integrantes do grupo, de forma que seus partícipes concordaram em retratar uma mulher, que expusesse toda trama por meio de um monólogo, no qual haviam nuanças características das contações de histórias.

Dessa forma, rememoramos o que Benjamin (1994) fala acerca da morte da narrativa em detrimento da criação do romance. Para esse autor, o romance continha as impressões de seu escritor em uma narrativa clássica com início, meio e fim, da mesma forma, com a qual seu epílogo era decidido, majoritariamente, pelo pensamento do seu criador.

Já a tradição da oralidade, traz consigo características inerentes a contação de história na qual é possível ao narrador, situar-se em um determinado ambiente, de forma que o texto expresso pode ser adaptado às realidades com as quais ele interage, ou seja, quando conta uma história o narrador coloca-se no mesmo território do seu interlocutor, que se sente abraçado e incluso pelo conteúdo apresentado oralmente.

Desse modo, tanto as construções visuais quanto as textuais, foram elaboradas para transitar em diversos locais, adaptando a cena e o texto às demandas existentes na região na 
qual o processo era construído. De maneira que todo o processo criativo é permeado por construtos nos quais há uma significativa presença das memorações dessas mulheres nordestinas incorporadas tanto ao texto, quanto nas decisões acerca das imagens na especificidade dos adereços, cenários, figurinos e objetos de cena, como veremos nas seções subsequentes.

\section{O liame entre dramaturgia e artes visuais no processo criativo de Bonita Maria}

Inicialmente é necessário destacar a importância da participação da atriz Aline Lima no processo criativo do dramaturgo, pois, a mesma já vinha de outras experiências com teatro de rua e uma presença ativa em grupos folclóricos. Compor, textual e visualmente, o referendado espetáculo, foi um compromisso firmado por todos os artistas, em reuniões e ensaios, com duração total de quatro meses antes da sua estreia oficial, equivalente ao tempo cronológico da disciplina anteriormente mencionada neste escrito. Ressaltamos que trabalho em teatro é, sobretudo, coletivo.

Nos ensaios foi possível observar as marcações da atriz, bem como a preparação da mesma para a cena que começava a ser montada. Algumas marcações são trabalhadas por serem potências de energia transformadas em linguagem corporal, com a qual as atrizes comunicam-se com seus interlocutores. Nesse ponto de vista, o fato do dramaturgo acompanhar o trajeto do desenvolvimento dos exercícios da atriz, orientados pelo diretor do espetáculo, foi fundamental para escrita textual e visual de Bonita Maria.

No que tange ao texto propriamente dito, era necessário contar uma história que já faz parte do imaginário popular de forma fidedigna, todavia, sem cair no arcabouço perigoso das obviedades. Sendo assim, ir em busca do entendimento popular acerca da presença feminil no cangaço, foi uma pesquisa de campo produtiva para as várias demandas do referido processo criativo. Essas informações fazem parte da memória coletiva de mulheres bem como as dos próprios integrantes do grupo teatral. Tornando-se intrínseco esse estudo a uma pesquisa participante, justamente por envolver essas demandas presentes em todo ato criador.

Quando explana acerca das necessidades da pesquisa participante Brandão (1981) faz uma analogia às linguagens artísticas, de forma que suas observações nos sãos preciosas, pois apresentam o liame entre a cultura popular e a diversidade das mídias. Desse modo, assim como o autor referido, acreditamos que as fases de investigação para o processo criativo, por conter a participação popular das reminiscências comunitárias feminais, como já fora mencionado, proporcionam um maior diálogo entre a obra e seu público. 
Dramaturgos como Shakespeare tiveram origem puramente popular, assim como a representação de suas tragédias e comédias. E os filmes de Chaplin ou a música dos Beatles não teriam sido possíveis se não estivessem enraizados no mundo do homem comum. (BRANDÃO, 1981, p.48).

Salles (2017) nos fala que os estudos genéticos, inicialmente tratavam de compreender os processos de produção na literatura, tendo nos manuscritos os seus objetos de estudo, todavia, sempre apontando para a transposição dos limites impostos pelas palavras. Sendo possível reconhecer os rastros deixados pelos artistas, acerca dos seus processos de criação, em diferentes manifestações das linguagens artísticas. "Processo e registros são independentes da materialidade na qual a obra se manifesta e independentes, também, das linguagens nas quais estas pegadas se apresentam". (SALLES, 2017, p.43).

Assim sendo, o texto e a imagem subsidiam um ao outro no processo criativo, facilitando os desdobramentos de ambos. Pensamos imagens e escrevemos de forma imagética. Vemos uma imagem e a concebemos por meio de fragmentos narrados na construção de nosso raciocínio. Tais frações, são identificadas em diversificados momentos criativos, surgindo com ideias e tomando corpo por meio de desenhos, fotografias, anotações, poesias, pinturas, etc. Acerca disso Zamboni (2006), vai nos dizer:

\footnotetext{
$\mathrm{Na}$ esfera da criatividade, as primeiras ideias, ainda num estado pré-consciência, não surgem de forma clara e cristalina, elas precisam tomar alguma forma apreensível pelo aparato racional para serem trabalhadas, ou seja, é necessário submeter a ideia a alguma forma de linguagem, sejam palavras, fórmulas ou símbolos. (ZAMBONI, 2006, p.33).
}

Em Bonita Maria, verificou-se a utilização para os cenários, figurinos e objetos de cena que buscavam na cor azul, quebrar um pouco esse estereótipo da sequidão da fisiografia caracterizada como sendo predominante na região Nordeste. $\mathrm{O}$ universo que permeia a vida do cangaço, não se restringia à região da caatinga, nem a áreas muito secas, eles percorriam outros territórios com a presença da vasta fauna e flora do Nordeste do Brasil. Com vistas nisso, o próprio diretor do espetáculo, Elias de Lima, já trazia para sua cena ideias de como trabalhar a presença da água, dessa forma se faz importante destacar à iluminação das cenas, idealizada por Mayra Costa, propiciando uma maior ruptura cromática de uma estereotipia visual e textual que traduziram essa região ao longo dos anos.

Segundo Albuquerque Júnior (2011), em sua obra A invenção do Nordeste e outras artes, ao longo percurso transcorrido pela arte, que resultou no que conhecemos como a 
estética da seca, foi prioritariamente incorporado em cores e texturas remetendo aos tons de terra. Tal ocorrência se deu com a necessidade em representar uma cultura abrasileirada em sua essência e artistas foram em busca dessas referências na literatura, do romance de 30, com $\mathrm{o}$ intuito de "oferecer sentido às várias realidades do país a desvendar a essência real do Brasil real”. (ALBUQUERQUE JÚNIOR, 2011, p.123).

\section{A criação da personagem}

Anteriormente foi destacado a presença das anamneses das mulheres da região Nordeste na construção deste processo criativo. No entanto, faz-se necessário salientar que alguns dados históricos, por serem mais precisos a exemplo do nome, data e local de nascimento, genealogia e relações intersociais que permearam a vida de Maria Bonita e as demais colegas do cangaço, foram fidedignas à vida real dessas personas. Dessa forma, o grupo de pesquisa teatral, tenta contribuir para o achatamento da invisibilidade da mulher no cangaço, assim como ocorre nas demais culturas, que trazem majoritariamente para à cena histórica, o protagonismo masculino.

Junto ao pensamento do coletivo Semente Contemporânea, destacamos como forma de agradecimento público, as colaboradoras que emprestaram suas memórias acerca do mito da mulher no cangaço para criação do espetáculo Bonita Maria, a saber: Salete Farias, nascida no município de Campina Grande (PB), estilista vinda de uma família de costureiras; Cândida da Nóbrega, natural do município de Patos (PB), professora e poetiza; Sandra Durval, nativa de Caruaru (PE), artesã e gerente de loja em um mercado de artesanato; Maria da Silveira, oriunda do Crato (CE), feirante e dona de estabelecimento comercial em um mercado público. Moradora de região paraibana há muitos anos, a atriz Aline Lima, por ser natural de São Paulo, capital, trouxe outras nuanças e contextualizações para uma mulher cangaceira em sua brasilidade mais ampla.

Bonita Maria, poderia ser qualquer mulher do cangaço, abrindo margem considerável para diversas situações vividas em semelhança por outros corpos femininos da época. Nesse sentido, Pallottini (1989) vai nos dizer que criar uma personagem dramaturgicamente não significa fazer uma cópia real de uma pessoa conhecida pelo autor do texto. "Mas de criar um ser de ficção, que reúna em si condições de existência; que tenha coerência, lógica interna, veracidade. Um ser que poderia ter sido, não necessariamente um ser que é". (PALLOTTINI, $1989, \mathrm{p} .12)$ 
Quando fora proposto ao grupo discorrer acerca da vida de uma personagem cangaceira, antes de sua imersão ao universo do banditismo, por conseguinte marginal, buscou-se apresentar ocorrências diversas nas quais seu corpo era colocado em situações marginalizadas, a exemplo dos casamentos arranjados, culminados com noites de núpcias caracterizadas pela violenta posse dos corpos, em atos de estupro, mascarados pelas conveniências de uma sociedade patriarcal.

As muitas infâncias interrompidas, o controle absoluto de seus passos, todas essas violências exercidas aos olhos da lei, em uma sociedade majoritariamente machista, que assim como nos rememora Foucault (1999), vigiava e punia tudo o que propiciasse gozo e prazer. Havia uma imposição ao corpo feminino, como uma propriedade do estado. Esse corpo controlado, mutilado, violentado, seduzido, oprimido, mas que ganha força ao tentar se desvincular do que lhes era imposto, de forma autoritária, como única forma de vida. O que essas mulheres tentavam era, sobretudo, escapar dos seus destinos sombrios, expostos a céu aberto, impostas pela cultura dos anos 1930, cronologicamente mais atrasada, quando comparado aos dias atuais.

É nesse contexto de sufocamento do corpo feminil que essa mulher surge no cangaço, em busca de formar uma nova identidade que lhes retirasse as amarras coercivas nas suas diversas situações de convivência social. Por esse ponto de vista, ter o direito de escolha é romper com um jugo patriarcal, procurando alternativas para viver contra um sistema dominante, ainda que inconsciente dos mecanismos que propiciassem uma maior compreensão do que ocorria com elas mesmas, devido à falta de acesso à educação, em 1930, que englobasse questões de gênero, direitos humanos e movimentos feministas. "O advento da história das mulheres deu-se na Grã-Bretanha e nos Estados Unidos nos anos 1960 e na França uma década depois. " (PEEROT, 2007, p.19).

Dessa forma, exigir daquelas mulheres, situadas em um espaço e tempo diferenciado do restante do mundo contemporâneo é algo tão desumano quanto o que elas vivenciaram. É justamente nesse aspecto que surge à história de Bonita Maria, sem grandes lentes detalhistas sobre vários aspectos do banditismo, por estarem imersa à subcultura do cangaço, mas que busca a presença de uma mulher ancestral. Tal figura, sobrevivente até os dias de hoje, por meio dos relatos de outras mulheres, levando em consideração, especialmente, o que elas carregavam, neste imaginário, e que pudesse vir à tona de forma poética na linguagem plástica e textual do teatro.

No livro, Mulheres que correm com os lobos, que trata dos mitos e histórias do arquétipo da mulher selvagem, maiormente, com a contação de histórias femininas no 
contexto cultural das américas, a autora Estés (1994), destaca que Jung certa vez notou que nada é perdido na psique. "Podemos ter a confiança de que tudo o que foi perdido na psique ainda está lá. Portanto, esse repositório da intuição instintiva das mulheres nunca se perdeu realmente, e tudo o que estiver encoberto poderá voltar a ser exposto”. (ESTÉS, 2012, p.107).

Sendo assim, consideramos o processo criativo como um construto coletivo no qual através da atriz, presente no grupo, dona do corpo no qual todas as construções seriam visíveis e audíveis, bem como as demais mulheres escutadas no processo de criação, sobre a vida da cangaceira, trouxeram subsídio significantes para a cena do referido espetáculo.

Uma mulher que encontrara um amor, não pelo outro do bando a quem se fazia visível, muito menos aos demais exteriores à pequena comunidade que lhe cercava. $\mathrm{O}$ amor era, acima de tudo, à sua própria liberdade, dentro dos limites de seu tempo, no qual ser vidente era espelhar-se, percebendo-se como alguém muito maior do que lhes eram apresentadas como única forma de vida.

No documentário Feminino e Cangaço de Viana e Neto (2016), que faz uma leitura acerca da questão de gênero presente no fenômeno social em si, a cangaceira Dadá, sobrevivente ao genocídio do cangaço, utiliza-se de sua fala para afirmar que as mulheres do bando, não eram tratadas enquanto domésticas, nem desempenhavam essa função, os homens cozinhavam para todo o grupo e lavavam suas próprias roupas. As mulheres tinham prerrogativas de origem machista, uma obrigação que consistia em estarem sempre bem vestidas, perfumadas e ornadas pelas muitas joias, as quais seus companheiros lhe presenteavam, adornos estes oriundos dos vários saques realizados pelo bando.

Bonita Maria é o título do espetáculo, sua personagem chama-se Maria de Dea, a Deinha na fase pueril, Maria de Zé de Neném quando obrigada a se casar, e depois a Maria do Capitão, na ocasião de sua ingressão ao grupo de Lampião, em acordo com a evolução dos fatos correspondentes as fases de sua história. Nessa lógica, Alschitz (2012) vai nos dizer que cada personagem traz em si não apenas o nome próprio, mas vários outros, essa denominação deve ser bem analisado em acordo com "as leis que lhe correspondem". (ALSCHITZ, 2012, p.107).

Com tudo o que fora elencado até agora, destacamos que a personagem elaborada, neste processo de criação, que engloba os limites do texto e da concepção visual, tinha um caráter onírico e universal, justamente por trazer em si esses construtos de uma memória coletiva acerca de uma mulher corajosa, que lançava fora uma vida oprimida para abraçar novas formas de ser e estar no mundo, mais aproximada da liberdade. Mesmo que essa emancipação dos seus grupos sociais dos quais eram nativas, significasse manter-se escondida 
dentro da vegetação espinhosa da caatinga, fugir da polícia, encarar as diversas ameaças de morte e tocais, sem nenhum conforto, nem o direito de crias seus filhos, era uma vida melhor do que aquela imposta de forma ditatorial em suas comunidades de origem.

\section{O cenário figurino}

O grupo Semente Contemporânea, responsável pela criação de Bonita Maria, não contou com nenhum auxílio financeiro ou edital de fomento, no início de suas atividades. Dessa forma, foi necessário construir um espetáculo com elementos pré-existentes. Nessa continuidade, a atriz trouxe para um dos primeiros ensaios um vasto guarda-roupas contendo seis peças, oriundas de distintas apresentações suas em quadrilhas juninas, e grupos folclóricos existentes no interior da Paraíba.

O que fazer com tantos vestiários, foi uma decisão do diretor de arte, este aproveitou as vestimentas a fim de compor a própria cenografia do espetáculo. De maneira que pudesse trazer para a cena, uma vida anterior à peça teatral, na qual havia indícios dessa persona, incorporada pela atriz, em momentos de grande significado parta a mesma. Essas manifestações populares, têm s importâncias na cultura popular e imaterial na nossa região, nas quais, vale salientar foram incorporados, visualmente, a própria figura estética do cangaceiro.

A cenografia sofre influência direta das obras de Frida Kahlo, Meu vestido pendurado ali (1933) e Memória, o coração, (1937), ambas com autoria da pintora mexicana, amplamente conhecida no Brasil. As roupas para Kahlo não eram meras opções estética, mas tratava-se de uma escolha consciente de como a artista queria ser vista. Sua identidade por meio do visório, reflete uma marca intrínseca, a sua forma de ser e estar no mundo, uma decisão e posição plástica ligada a um ser vidente e visível que compreendia e divulgava toda uma cultura indígena. Aqui esclarecemos que compreendemos a identidade enquanto uma construção social e cultural (SILVA, 2000, p.76).

Da mesma forma havia com os cangaceiros, uma estética do cangaço, na qual a vestimenta, o seu uniforme de batalha, era ornado para causar encantamento e respeito, ao mesmo tempo em que incorporava uma total funcionalidade, protegendo-os do sol e da vegetação espinhosa da caatinga. Anexadas à peça de roupa, encontravam-se armas, munições, cobertores, canecas, prato, talher, suporte para objetos pessoais e cantis para água.

Essas vestimentas sinalizavam uma cultura própria, todavia amparada por outros construtos já existentes, pois eram diretamente adaptações das roupas dos vaqueiros, 
formadas dentro da própria cultura nordestina ao longo do tempo. Sendo assim, essas “identidades são formadas culturalmente, o que significa dizer que devemos pensar as identidades sociais como construídas no interior da representação, por meio da cultura, e não fora dela”. (RODRIGUES; ABRAMOWICZ, 2013, p.21-22).

Tais construtos visuais e culturais são a forma com a qual essas mulheres e homens comungavam de um mesmo entendimento, no que diz respeito a um ser vidente que almejava tornar-se visível, ou seja, o reconhecimento das importâncias de suas próprias vidas. O que a cenografia sugeriu, e fora acatada por todo o grupo, consistiu em dependurar as vestimentas femininas, representando simbolicamente as outras 60 mulheres do cangaço. Tal elaboração, amparava os três atos, no qual se estruturava o texto, contemplando à presença das mulheres, apresentadas no desenvolvimento da trama, na medida em que narram a vida da personagem. A cenografia flutuante ainda simboliza as memórias coletivas e individuais feminais susoditas.

O cenário de roupas posicionadas de forma aérea, também encontra respaldo na fotografia datada em meados do ano de 1937, com autoria de Benjamim Abrahão, na qual a própria Maria Bonita aparece ao lado de dois cães. Etérea, sentada num tamborete invisibilizado pelo fotógrafo, numa das mais belas imagens, simbolizando toda a poeticidade e elegância da presença feminina no cangaço. Essa fotografia, junto as duas imagens mencionadas da obra de Frida Kahlo, formam o conceito visual do cenário de Bonita Maria disposta em seu conceptboard, um quadro de referências contendo imagens, que podem ou não serem feitas por nós, com o intuito de elaborar um conceito coeso para um determinado fim artístico ou criativo.
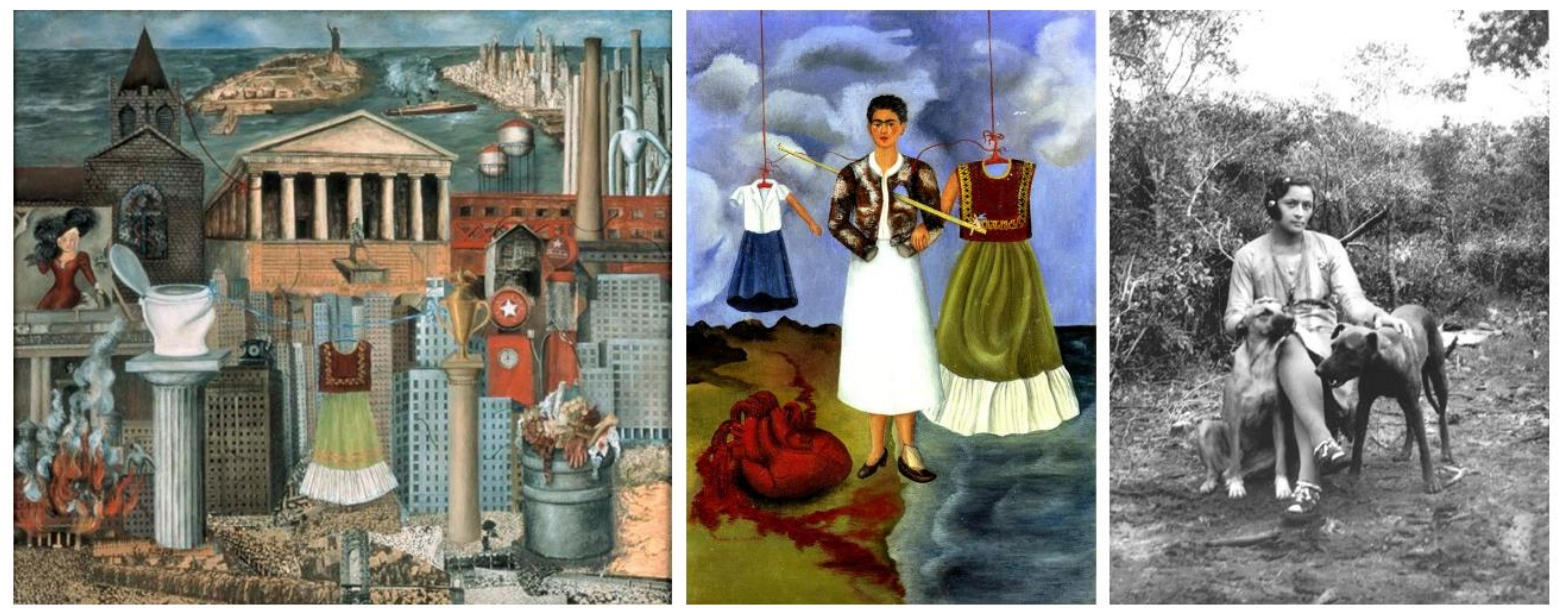

Figura 1- Conceptboard do cenário de Bonita Maria.

Fonte: arquivos do grupo Semente Contemporânea. 
Outrossim relacionado ao quadro montado para esta conceituação visual da grafia da cena, diz respeito ao ato trasncriativo do fenômeno em si, quando as muitas referências que fazem parte do repertório cultural de um agente, trabalhando em um determinado processo criativo, pode abranger uma mescla que envolvem temporalidades, universos e expressões.

Corroborando com nosso raciocínio temos Alves (2010), que enxerga a relação entre um pintor; compreendido de forma mais ampla enquanto um sujeito dominante de uma linguagem artística, logo, artista; e seu espectador, é mediada pela criação, essa por sua vez envolve relações de sentidos reconhecidos pela visão. "No ato criativo, os sentidos de abrem para se comunicarem com outros mundos, outros tempos e outros discursos, o sentido de uma pintura se abre para sua própria história”. (ALVES, 2010, p.245).

Além das vestes flutuantes, uma arara com outras peças de roupas fica situada no palco, contendo dois figurinos usados pela personagem que evolui no decorrer da trama. A atriz metamorfoseia-se em cena por meio da troca de roupas, com essas vestes colocadas sobre uma segunda pele. "O efeito de força e energia que o ator é capaz de manifestar é reforçado e elevado pela metamorfose do figurino em si, numa relação recíproca de troca: ator-corpo, ator-figurino, ator no figurino." (BARBA; SAVARESE, 1995, p. 219).

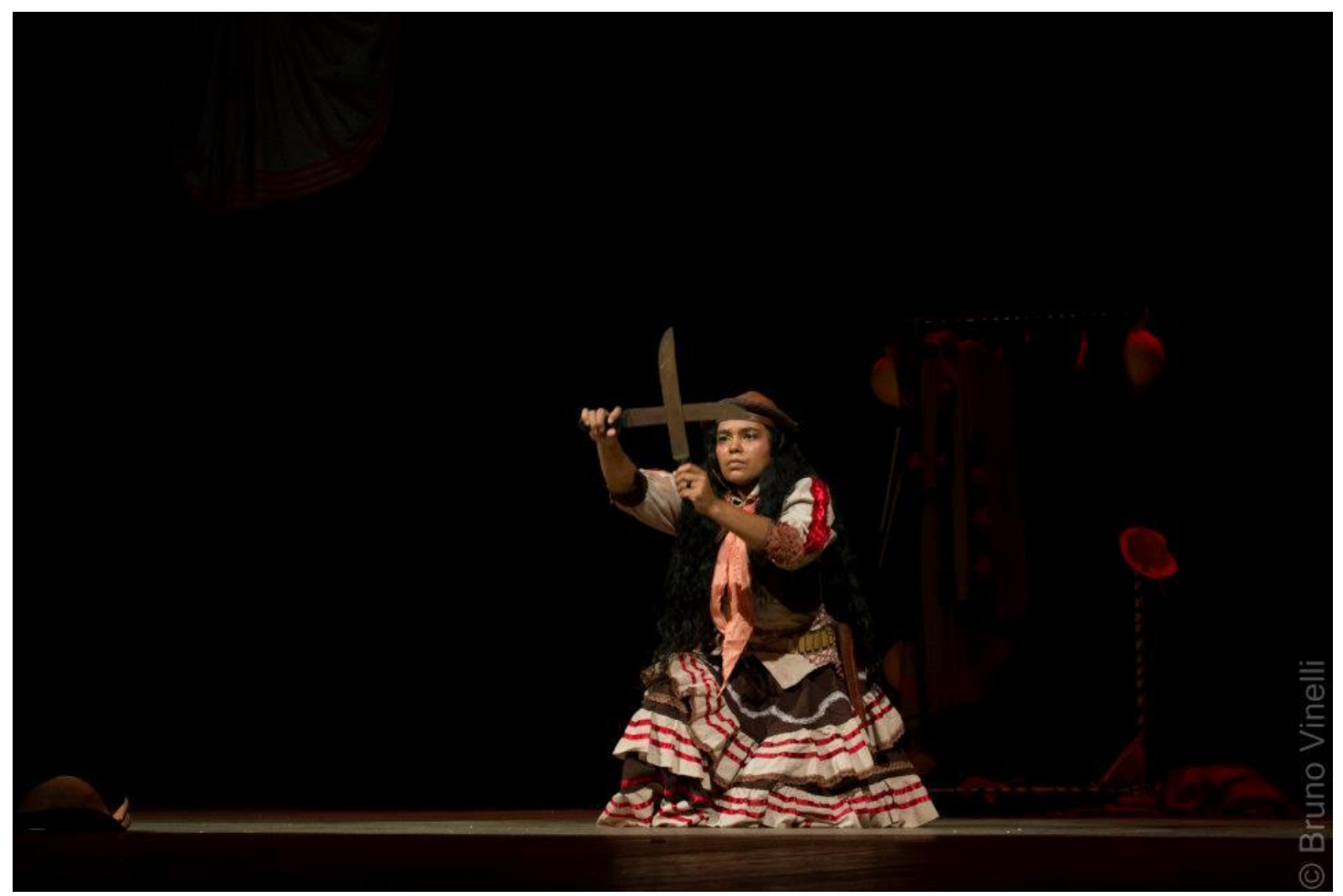

Figura 2- Espetáculo Bonita Maria, cenário por trás da atriz. Foto: Bruno Vinelli. 
Fonte: arquivos do grupo Semente Contemporânea.

A ação de vestir-se no palco sustenta visualmente a história contada por meio dos conflitos necessários para a desenvoltura da própria narrativa. Tais vestuários posicionados nesta estrutura de chão, trazem em seu significado um fato interessante sobre o cangaço, os seus integrantes carregavam consigo todas as suas posses, eles eram donos de tudo aquilo que seus corpos podiam carregar.

A direção de arte do espetáculo optou por essa construção, com o intuito de facilitar os movimentos da atriz em concomitância à poeticidade da própria personagem, no que se refere a possibilidade de se transformar em diversas personas na frente de sua plateia. Desse modo, o auxílio de uma luz composta para a cena, bem como a sonorização, também elaborada para esse fim, por meio desses múltiplos profissionais do teatro, em seus processos de criação, possibilita o jogo ficar completo, propiciando o fenômeno da poesia visível e audível, o encantamento propriamente dito, o fenômeno teatro.

\section{Adereços, figurinos, objetos de cena e maquiagem}

Esta seção é dedicada aos quatro elementos em suas fisicalidades inerentes à cena teatral. Pontuaremos suas funções intrínsecas ao recorte desse estudo, o âmbito textual e os aspectos visuais. Adereços, figurinos, objetos de cena e maquiagem traduzem, no campo do simbólico, as nuanças elaboradas no texto de forma que apontaremos as mais importantes na obra Bonita Maria.

Cada adereço traz em si seu significado e sua simbologia, dessa forma auxilia na narração da história contada, a exemplo dos chapéus de couro usados pela personagem, estes a transformam em outras figuras na cena. A adereçagem também tem sua aplicabilidade nos figurinos, envelhecendo-os ou destacando neles cores, formas, texturas em seus variados contextos necessários às especificidades de cada trabalho. Com relação aos trajes estudados, o vestuário principal da personagem, foi reaproveitado de peças antigas da atriz, sendo customizado pelo designer de moda e artista visual, Adriano Bezerra, que lhe deu um novo significado, houve a necessidade de um tingimento para melhor compor à luz elaborada por Mayara Costa. Compreender a luz é a forma de tornar visível tudo o que é criado para o teatro.

Com relação aos objetos de cena, a direção de arte, solicitou a presença uma boneca contida no texto, de forma que fosse inspirada nas bonecas nordestinas, comumente 
encontradas nos mercados públicos e feiras de artesanato ocorrentes na região. Esse objeto precisava ser mais maleável, ter um tamanho maior e com cabelos longos, semelhante aos da atriz, uma vez que era uma quase réplica de sua figura.

Apesar de ter seu caráter lúdico, esse artefato tem a intenção de despertar a mulher imersa no conto de fadas, para inseri-la numa determinada realidade, posta em cena. Da mesma forma como ocorre no conto Vasalisa que inspira sua utilização na cena referenciada. Tal contação de história, tem sua matriz transcrita no livro Mulheres que correm com os lobos: mitos e histórias do arquétipo da mulher selvagem, de Clarissa Pinkola Estés. No capítulo três desta obra, também mencionada em outra seção, a autora trata da importância da intuição feminina passada de mãe para filha, ou seja, de uma geração para outra.

Vasalisa é uma história da transmissão da bênção do poder da instituição das mulheres de mãe para filha, de uma geração para outra. Esse poder, o da intuição tem a rapidez de um raio e é composto de visão interior, audição interior, percepção interior e conhecimento interior. (ESTÉS, 1994, p.106).

A boneca Deinha que representa Maria Bonita, na fase infantil, assume uma elipse temporal e narra a vida da personagem desde o convívio pacífico com sua mãe, até o momento do seu primeiro casamento que fora arranjado. Outros objetos de cena com igual importância para obra, constam em dois facões usados pela personagem, vale ressaltar que esses objetos já faziam parte do universo da triz, no teatro de rua e outras manifestações folclóricas. 


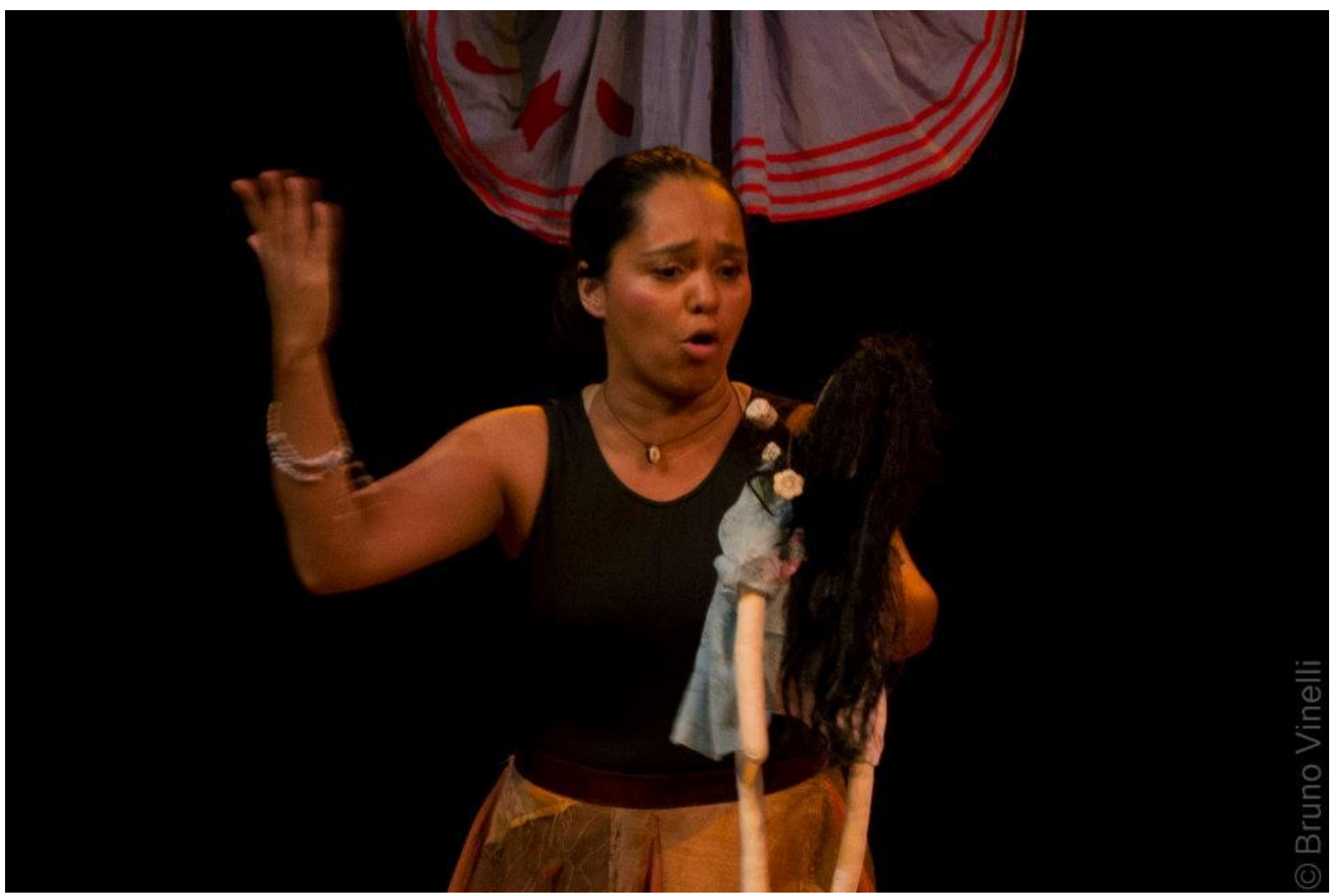

Figura 3- Espetáculo Bonita Maria, a atriz Aline Lima manuseia a boneca Deinha. Foto: Bruno Vinelli.

Fonte: arquivos do grupo Semente Contemporânea.

Não concebida pelo texto, outra construção cênica, idealizada pelo diretor do espetáculo merece destaque, trata-se de um ser onírico que surge no desfecho da peça, na qual o próprio diretor entra em cena encarnado um personagem. Utilizando a dança butô, essa figura simboliza a morte dos cangaceiros, bem como anuncia à volta de seus corpos para o elemento terra. As visualidades obedecem à paleta de cores da direção de arte, complementadas na adereçagem desse figurino por meio de cipós e galhos. Tanto os facões, mencionados anteriormente, quando o ser onírico surge num mesmo momento na cena de Bonita Maria.

A maquiagem para esse personagem, foi idealizada para trazer o aspecto de uma criatura vinda do barro, da terra, para esse efeito foi utilizado talco misturado com leite de magnésio e massa de argila para artesanato. O maquiador Willians Muniz faz uma participação no espetáculo estreante, momento no qual prestou um workshop com orientações específicas para a atriz referente a forma de preparar sua make para a respectiva personagem . 


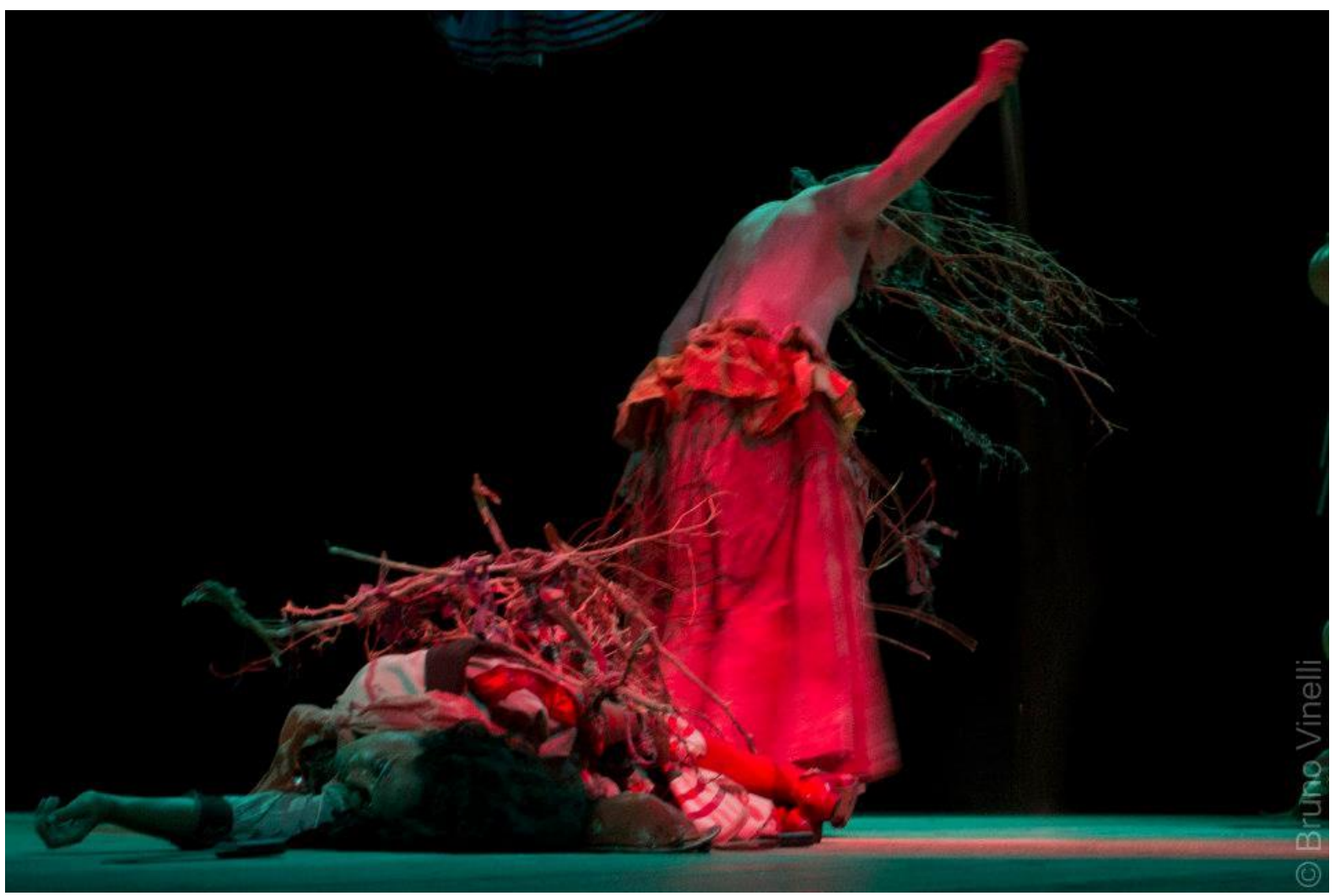

Figura 4- Espetáculo Bonita Maria, presença dos facões e figura onírica. Foto: Bruno Vinelli.

Fonte: arquivos do grupo Semente Contemporânea.

Outro construto que envolvem objetos de cena consta em onze chapéus de vaqueiros que simbolizam as 11 cabeças decapitadas pela polícia, numa referência à memória das pessoas que conviveram diretamente com Maria Bonita e foram assinadas junto com ela. Tal foto mencionada, famosa por sua brutalidade, é facilmente encontrada na internet. A personagem chama por todas as vítimas em um determinado momento da sua performance. "Além de mais, a morte, que põe um fim à vida fisiológica, não interrompe bruscamente a corrente dos pensamentos, de modo que eles se desenvolvem no interior do círculo daquele cujo corpo desapareceu". (HALBACKS, 1990, p.60).

\section{Considerações finais}

Quando afirmamos que compreendemos os processos de criação como uma transcriação, reforçamos ideia que nesses movimentos de tradução e recriação estão incorporados, em nossas mentes, por meio das teorias e ensinamentos diversos, a presença do conhecimento feminino. Provindos de vários momentos, essa percepção de mundo, oriundos 
das mulheres, estão dentro dos processos criativos, sua existência abriga no campo das ideias coletivas, configurando-as com mais sapiência e lucidez.

Com esse levantamento e análise de dados, verificamos que todas as figuras femininas mencionadas neste escrito, sejam as pesquisadoras, que deram sustento com suas obras de arte, estudos e teorias utilizadas no processo de criação do referido espetáculo, sejam as mulheres, em sua diversidade de atribuições, que emprestaram suas memórias para o construto da obra Bonita Maria, todas são mulheres autoras e coautoras merecendo seu reconhecimento em um documento elaborado na linguagem acadêmica como é o caso deste artigo.

Por fim, e não menos importante, se faz o agradecimento a iluminadora Mayara Costa e a atriz Aline Lima, que encarna a personagem. Esperamos que esse escrito encontre e afete outras Bonitas Marias, as quais encontrem substratos teóricos e venham discorrer acerca de suas produções em outras pesquisas, tendo em mente a pluralidade da cultura do universo feminino, tanto expresso na forma das artes cênicas, quanto nas artes visuais, além das demais possibilidades das linguagens em sua diversidade de suportes e mídias.

\section{Referências}

AGAMBEN, G. O que é o Contemporâneo? In: O que é o Contemporâneo? e outros ensaios. Chapecó: Argos, 2009. 92p.

ALBUQUERQUE JÚNIOR, D. M. A invenção do Nordeste e outras artes. São Paulo: Cortez, 2011.

ALSCHITZ, J. 40 questões para um papel: um método para autopreparação do ator. São Paulo: Perspectiva. 2011. 116p.

ALVES, F. C. A filosofia Merleau-pontiana e a arte. Revista Palíndromo: Florianópolis, v.3, n.3, p.223-255. 2010.

BARBA, E.; SAVARESE, N. A arte secreta do ator: dicionário de antropologia teatral. Campinas - SP: Editora da Unicamp. 1995. 272p.

BRANDÃO, C. R. (Org.). Pesquisa participante. São Paulo: Editora Brasiliense, 1981. 211p.

CAMPOS, H. Da transcriação - poética e semiótica da operação tradutora. Belo Horizonte: Viva Voz, 2011. 162p.

ESTÉS, C. P. Mulheres que correm com os lobos: mitos e histórias do arquétipo da mulher selvagem. Rio de Janeiro: Editora Rocco. 1994. 628p. 
HALBWACHS, M. A memória coletiva. São Paulo: Edições Vértice/Editora Revista dos Tribunais Ltda. 1990. 190p.

MARTINS, R.; TOURINHO, I. Educação da Cultura Visual: conceitos e contextos. Santa Maria: Editora da UFSM, 2011. 323p.

MELLO, F. P. A estética do cangaço. Disponível em: https://www.youtube.com/watch?v=RQRbcI4Kauc. Acesso em: 15 abril 2020.

MERLEAU-PONTY, M. O olho e o espírito. São Paulo: Cosac Naify, 2004. 192p.

PALlOTTINI, R. Dramaturgia: a construção do personagem. São Paulo: Editora Ática, 1989. 156p.

RODRIGUES, T. C.; ABRAMOWICZ, A. O debate contemporâneo sobre a diversidade e a diferença nas políticas e pesquisas em educação. Educ. Pesqui., São Paulo, v. 39, n. 1, p. 1530, jan. /mar. 2013. Disponível em: http://www.scielo.br/pdf/ep/v39n1/v39n1a02.pdf. Acesso em: 02 abr. 2020.

SAlleS, C. A. Da Crítica Genética à Crítica de Processo: uma linha de pesquisa em expansão. SIGNUM: Estud. Ling., Londrina, n. 20/2, p. 41-52, ago. 2017.

SALLES, C. A. Gesto Inacabado: processo de criação artística. São Paulo: Annablume, 2007. 180p.

SILVA, T. T. Identidade e diferença: a perspectiva dos estudos culturais. Petrópolis: Vozes, 2000. 136p.

PERROT, M. Minha história das mulheres. São Paulo: Contexto, 2007. 192p.

VIANA, L.; NETO, M. Feminino Cangaço. Disponível em: https://www.youtube.com/watch?v=wsTCQ7LOeds . Acesso em: 16 abril 2020.

ZAMBONI, S. A pesquisa em arte: um paralelo entre arte e ciência. Campinas: Autores Associados. 2006. 123p. 